\title{
Insight into Structural Features of Magnetic Kaolinite Nanocomposite and Its Potential for Methylene Blue Dye Removal from Aqueous Solution
}

\author{
Izzan Salwana Izman', Mohd Rafie Johan², Ruhaida Rusmin ${ }^{1, *}$ \\ ${ }_{1}^{1}$ Faculty of Applied Sciences, Universiti Teknologi MARA (UiTM), Negeri Sembilan branch, Kuala \\ Pilah campus, 72000 Kuala Pilah, Negeri Sembilan, Malaysia. \\ ${ }^{2}$ Nanotechnology \& Catalysis Research Centre (NANOCAT), University of Malaya, Kuala Lumpur \\ 50603, Malaysia.
}

Received: 11th November 2021; Revised: 27th January 2022; Accepted: 27th January 2022 Available online: $1^{\text {st }}$ February 2022; Published regularly: March 2022

\section{Abstract}

An in-depth understanding on the structural features of engineered magnetic adsorbent is important for forecasting its efficiencies for environmental clean-up studies. A magnetic kaolinite nanocomposite (MKN) was prepared using Malaysia's natural kaolinite via co-precipitation method with a three different clay: iron oxide mass ratio (MKN 1:1, MKN 2:1 and MKN 5:1). The morphology and structural features of the magnetic composites were systematically investigated using techniques, such as: Fourier transform infrared spectroscopy (FTIR), scanning electron microscope (SEM), surface area analysis (BET), Vibrating Sample Magnetometer (VSM), and zeta potential measurement. The removal efficiencies of the adsorbent for Methylene Blue (MB) dye were studied in batch method as a function of $\mathrm{pH}$ and initial concentration. MKN1:1 demonstrated the highest magnetisation susceptibility $\left(\mathrm{M}_{\mathrm{s}}\right)$ of $35.9 \mathrm{emu} / \mathrm{g}$ with four-fold-increase in specific surface area as compared to the pristine kaolinite. Preliminary experiment reveals that all MKNs showed almost $100 \%$ removal of $\mathrm{MB}$ at low initial concentration $(<50$ ppm). The spent MKN adsorbent demonstrated an easy recovery via external magnetic field separation and recorded maximum adsorption capacity of $18.1 \mathrm{mg} / \mathrm{g}$. This research gives an insight on the surface characteristics of magnetic clay composite for potential application as an effective and low-cost adsorbent in treating dye contaminated water.

Copyright (C) 2022 by Authors, Published by BCREC Group. This is an open access article under the CC BY-SA License (https://creativecommons.org/licenses/by-sa/4.0).

Keywords: Magnetic; Kaolinite; Nanocomposite; Structural; Dye

How to Cite: I.S. Izman, M.R. Johan, R. Rusmin (2022). Insight into Structural Features of Magnetic Kaolinite Nanocomposite and Its Potential for Methylene Blue Dye Removal from Aqueous Solution. Bulletin of Chemical Reaction Engineering \& Catalysis, 17(1), 205-215 (doi: 10.9767/bcrec.17.1.12733.205-215)

Permalink/DOI: https://doi.org/10.9767/bcrec.17.1.12733.205-215

\section{Introduction}

Untreated dyes effluent has become a major source of water pollution especially in developing countries. Methylene blue (MB) is an example of cationic synthetic dye commonly used in the textile and pharmaceutical industry [1]. Exposure to excessive MB could cause harmful ef-

\footnotetext{
* Corresponding Author.

Email: ruhaida@uitm.edu.my (R. Rusmin);
}

fects [2] especially to aquatic life since the intense-coloured MB can block the light penetration and oxygen transfer in water. Therefore, various techniques, such as photocatalysis, adsorption, coagulation/flocculation, and filtration, were developed to solve the dye contamination issues in water resource. Among those techniques, adsorption is considered as a good approach due to its low cost, high performance, and simple operation $[3,4]$. 
Clay minerals like bentonite, palygorskite, and kaolinite have received great interest either as a catalyst or pollutant adsorbent due to its non-toxicity, inexpensive and high availability [3,5,6]. Malaysia has approximately 112 million tons of kaolinite reserve $[7,8]$ with a total export value of Malaysian Ringgit 26 million (approximately USD 6 million) in 2013 [8]. Under the Malaysia's National Mineral Industry Transformation Plan 2021-2030 (MIT 20212030 Plan), the government aim to prioritise local minerals like kaolinite over imported mineral commodities for domestic industries and research and development (R\&D) [9]. The local kaolinite is mostly used for paper coating, skincare products and engineering applications, whereas only a few scientific works reported its use as high value industrial products [7] including as material for water remediation. As a non-expanding clay, kaolinite in general have a lower adsorption capacity for removal of water contaminants as compared to other swelling clays like montmorillonite. Nevertheless, research works on kaolinite's modification, especially in developing countries, are wellprogressing and have demonstrated a substantial efficiencies improvement in environmental clean-up studies $[1,10]$ that worth for further investigations.

The development of hybrid material like magnetic clay composite for water treatment application is blooming fast due to the attractive surface properties, less complicated preparation method and facile separation capabilities $[11,12]$. With the incorporation of magnetic particles like iron oxide into the clays' gallery or surface [13], the magnetic clays are easy to be separated from the reaction media through the external applied magnetic field. This modification can address the current recovery issue for spent clay adsorbents which require conventional filtration or centrifugation method that are either cost- or time consuming.

In recent literature, scientific works that carefully discuss the suitable composition ratio required for the synthesis of hybrid composite material are still lacking. Selecting a good compositional ratio is important from both structural and efficiencies perspective. The knowledge will ensure a balance engineering strategy between achieving the desirable structural features (e.g., strong magnetic susceptibility and high surface area) and maximising its performance (high percent removal of pollutant or adsorption capacity). This research aims to investigate the morphology and structural features of the magnetic kaolinite composite prepared via co-precipitation method with different kaolinite: iron oxide mass ratio. Spectroscopic and macroscopic techniques will be used to characterise the composites. The performance of magnetic composites against Methylene Blue removal will be investigated.

\section{Materials and Methods}

\subsection{Chemicals and Reagents}

Kaolinite (grade KM40) was purchased from Kaolin (Malaysia) Sdn. Bhd. The X-Ray Fluorescence (XRF) analysis supplied by the manufacturer (Reference no: SM-CR-SM4) is as follows: $\mathrm{Al}_{2} \mathrm{O}_{3}=32$ to $38 \%, \mathrm{SiO}_{2}=47$ to $53 \%$ and loss of ignition $=11$ to $14 \%$. Methylene Blue (C.I.52015) was obtained from Systerm (Malaysia), nitric acid $\left(\mathrm{HNO}_{3}, 96 \%\right)$ and ammonium hydroxide $\left(\mathrm{NH}_{4} \mathrm{OH}, 25 \%\right)$ by $\mathrm{R} \& \mathrm{M}$ chemicals (Malaysia), iron(III) chloride hexahydrate $\left(\mathrm{FeCl}_{3} .6 \mathrm{H}_{2} \mathrm{O}, 99 \%\right.$ purity) from $\mathrm{HmbG} \circledast$ chemicals (Malaysia), iron(II) sulphate heptahydrate $\left(\mathrm{FeSO}_{4} .7 \mathrm{H}_{2} \mathrm{O}, 99 \%\right.$ purity) was purchased from Bendosen (Malaysia), and sodium hydroxide (NaOH, 96\%) from Sigma Aldrich (Malaysia).

\subsection{Synthesis of Magnetic Kaolinite and Iron Oxide}

The iron oxide (IO) particle was prepared by dissolving a $3.1 \mathrm{~g}$ of $\mathrm{FeCl}_{3} .6 \mathrm{H}_{2} \mathrm{O}$ and $2.4 \mathrm{~g}$ of $\mathrm{FeSO}_{4} .7 \mathrm{H}_{2} \mathrm{O}$ in $50 \mathrm{~mL}$ of deionized water, separately [14]. Next, the $\mathrm{Fe}^{2+}$ solution was added into $\mathrm{Fe}^{3+}$ solution then was placed into a water bath and agitated $(200 \mathrm{rpm})$ at $60{ }^{\circ} \mathrm{C}$ in $30 \mathrm{~min}$. The agitation speed was further increased (400 $\mathrm{rpm})$ and $\mathrm{NH}_{4} \mathrm{OH}(25 \% \mathrm{v} / \mathrm{v})$ was added dropwise into the suspension until the solution turned to alkaline ( $\mathrm{pH} 8.9$ to 9.1) to precipitate the iron hydroxide. The suspension was aged for another 1 hour at the same temperature. The precipitation was collected using filtration and was thoroughly washed with deionized water and ethanol until a neutral $\mathrm{pH}$ was achieved. The IO precipitate then was dried at $110{ }^{\circ} \mathrm{C}$ for 3 hours, ground and sieved (200 mesh).

The preparation procedure of MKN was similar with the preparation of IO as described earlier, except that kaolinite suspension is added into the $\mathrm{Fe}^{2+}-\mathrm{Fe}^{3+}$ suspension via in situ approach according to our previous work [15]. Three calculated mass ratios of kaolinite: iron oxide which were 1:1, 2:1 and 5:1 was chosen to prepare the MKNs; later denoted as MKN 1:1, MKN 2:1 and MKN 5:1, respectively. First, a specific amount of kaolinite was added into the $\mathrm{Fe}^{3+}$ solution at $40{ }^{\circ} \mathrm{C}$ for 15 minutes. The $\mathrm{Fe}^{2+}$ solution was then added to the kaolinite $-\mathrm{Fe}^{3+}$ suspension and agitated. The addition of 
$\mathrm{NH}_{4} \mathrm{OH}(25 \% \mathrm{v} / \mathrm{v})$, aging, collection of $\mathrm{MKN}$ and the drying process were as similar as the procedure in the preparation of IO described earlier. The black precipitate of MKNs were ground, sieved (200 mesh) and kept in a dark and airtight container for further use.

\subsection{Characterizations}

Fourier-transform infrared spectroscopy (FTIR) spectrum was collected using FTIRSpectrum 400 spectrometer in the range of $4000 \mathrm{~cm}^{-1}-450 \mathrm{~cm}^{-1}$ at resolution of $4 \mathrm{~cm}^{-1}$ with 32 scans using the $\mathrm{KBr}$ pressing method. $\mathrm{KBr}$ pellets were prepared with a 1:200 mass ratio of sample and $\mathrm{KBr}$, respectively. The $\mathrm{X}$ ray powder diffraction XRD analysis was performed using D8 Advance X-Ray diffractometer
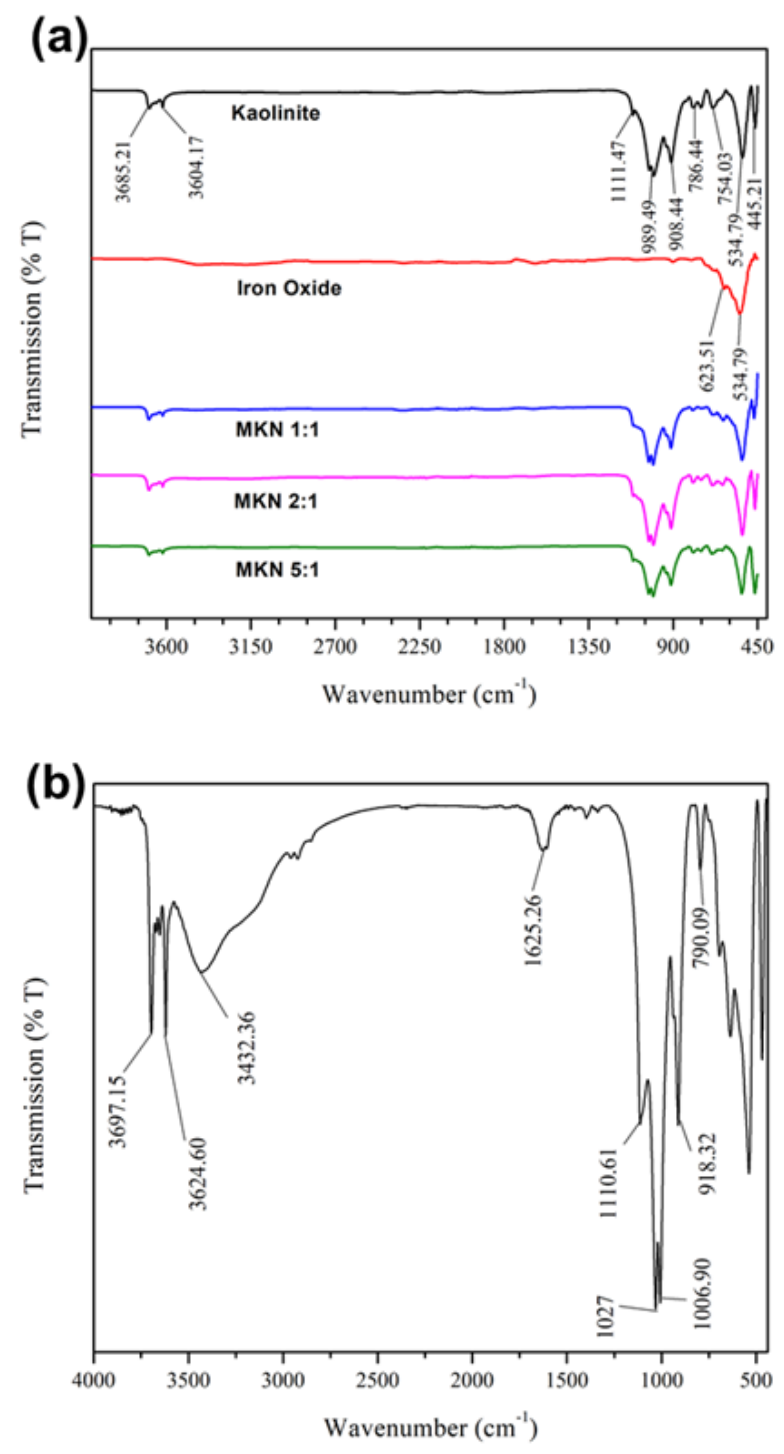

(Bruker AXS, Germany) with $\mathrm{Cu} \mathrm{Ka}$ radiation $(\lambda=0.15406 \mathrm{~nm})$ and the $2 \theta$ range from 5 to $80^{\circ}$. Scanning electron microscopy (SEM) images were acquired on a Quanta 450 FEG operated at $15 \mathrm{kV}$ accelerating voltage to observe the morphology and estimate the particle size of samples. The samples were prepared by direct deposition on an aluminium stub covered by a carbon grid and then coated with a thin layer of platinum ( 10 nm thick film). The Energy Dispersive X-Ray (EDX) analysis was performed simultaneously to determine the elemental composition ( $\mathrm{Al}, \mathrm{Si}, \mathrm{O}, \mathrm{Fe}$ ). To determine the surface porosity, the $\mathrm{N}_{2}$ adsorptiondesorption isotherm was performed at $-195{ }^{\circ} \mathrm{C}$ using Sorptometric1990 series. The BrunauerEmmett-Teller (BET) method was used to calculate the specific surface area and pore size of samples. Meanwhile, Barrett, Joyner and Halenda (BJH) method was used for the pore volume and size distribution. Prior analysis, a $20 \mathrm{mg}$ sample was placed into a clean and dry tube for degassing at $90{ }^{\circ} \mathrm{C}$ for 1 hour and then increase to $180{ }^{\circ} \mathrm{C}$ for 4 hours [16]. The weight of the sample before and after degassing will be recorded. Meanwhile the magnetization measurement of MKN was carried out using 7400 Series VSM System (Lake Shore, Ohio). The hysteresis measurements were performed at $300 \mathrm{~K}$ with magnetic field up to $0.9 \mathrm{~T}$ to obtain the demagnetisation corrections. Zeta potential measurements were performed using the Zetasizer Nanoseries instrument (Malvern, United Kingdom). The suspensions were prepared by mixing a $0.15 \mathrm{~g}$ sample in $15 \mathrm{~mL}$ electrolyte (deionized water) with selected $\mathrm{pH}$ val-

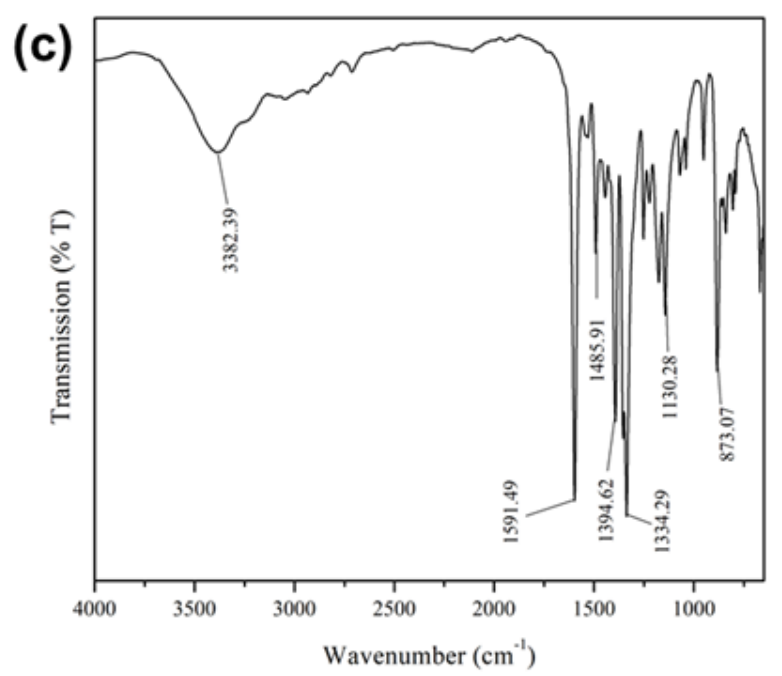

Figure 1. (a) FTIR spectra of raw kaolinite, iron oxide and magnetic kaolinite nanocomposite (MKN 1:1, MKN 2:1, MKN 5:1, (b) FTIR spectrum of MKN 1:1 after adsorption with Methylene Blue (MB loaded-MKN), (c) FTIR spectrum of methylene blue (MB). 
ues (pH 2 to 10). Next, the samples were homogenized for 1 hour at room temperature prior analysis and measurements were made in triplicates. The average value was reported.

\subsection{Adsorption Studies}

The Methylene Blue (MB) removal was studied using the batch equilibrium adsorption method. A stock solution (300 ppm) of MB was prepared in the deionized water followed by subsequent dilution. The experimental parameters such as initial concentration and $\mathrm{pH}$ were optimised to determine the equilibrium concentration. Pristine kaolinite was used as the control. A $0.125 \mathrm{~g}$ amount of adsorbate in MB solution $(25 \mathrm{~mL})$ of desired initial concentration $(5$ to $150 \mathrm{ppm}$ ) was agitated at $130 \mathrm{rpm}$ for 4 hours. Throughout the experiment, the samples were fully wrapped in foil to keep the dark condition for avoiding any potential lightdegradation.

After reaction completion, the adsorbent was separated by an external magnetic field using a magnetic bar. The dye concentration of supernatant was determined using the UV-Vis spectroscopy (T80+, PG instrument Ltd). The removal efficiency, $E$ (\%) was calculated (Eq. 1), as well as amount of dyes adsorbed, $q_{e}$, (Eq. 2), where the $[M]_{i}$ and $[M]_{f}$ denotes the concentration of MB before and after treatment $(\mathrm{mg} / \mathrm{L})$, respectively, $W$ is the mass of adsorbent (g), and $V$ is the volume of the solution (L).

$$
\begin{aligned}
& E(\%)=\frac{[M]_{i}-[M]_{f}}{[M]_{i}} \times 100 \% \\
& q_{e}=\frac{\left([M]_{i}-[M]_{f}\right) V}{W}
\end{aligned}
$$

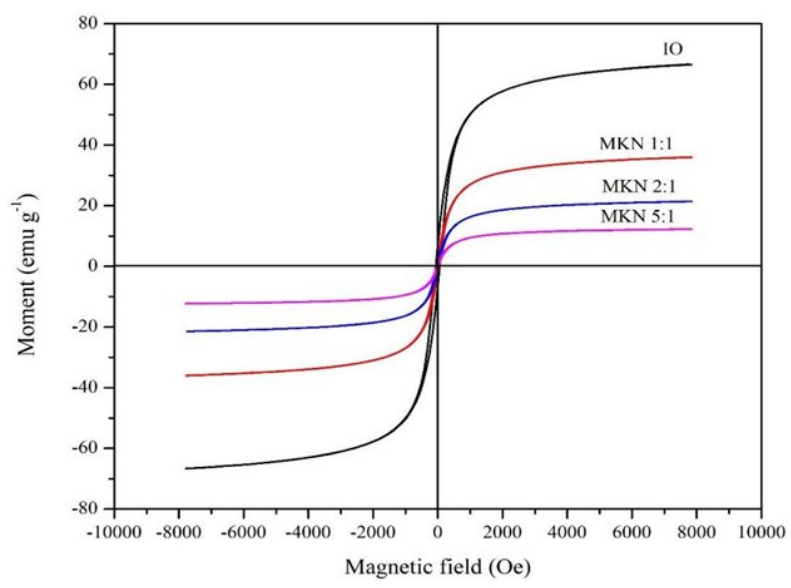

Figure 2. VSM curves of iron oxide, MKN 1:1, 2:1 and MKN 5:1.
The adsorption equilibrium data were then fitted to the Langmuir and Freundlich adsorption isotherm model.

\section{Results and Discussion}

\subsection{Characterization of Adsorbent}

The FTIR spectra of raw kaolinite, iron oxide and magnetic kaolinite composites are presented in Figure 1(a). Both the raw kaolinite and magnetic kaolinite nanocomposite (MKN) showed two bands at $3695 \mathrm{~cm}^{-1}$ and $3620 \mathrm{~cm}^{-1}$, which represent the $\mathrm{Al}-\mathrm{OH}$ stretching vibration in the clay's structure [17-20]. These bands were less intense in the MKNs spectrum indicating the possible exchange of $\mathrm{Al}^{3+}$ with $\mathrm{Fe}^{3+}$ on the surface of kaolinite [21]. Furthermore, acidic $\mathrm{Fe}^{2+} / \mathrm{Fe}^{3+}$ solution during the synthesis of MKN might promote partial Al dissolution from clays' gallery thus allowing the interchange of cations. The spectral bands at $1112 \mathrm{~cm}^{-1}$ and $1006 \mathrm{~cm}^{-1}$ in raw kaolinite denotes the $\mathrm{Si}-\mathrm{O}$ bending and stretching vibrations $[15,19,22]$. Meanwhile the band appeared at $910 \mathrm{~cm}^{-1}$ was corresponded to the $\mathrm{Al}-\mathrm{O}$ bending vibration $[19,20]$, whereas the band at $795 \mathrm{~cm}^{-1}$ and $755 \mathrm{~cm}^{-1}$ represents the $\mathrm{Si}-\mathrm{O}-\mathrm{Al}$ stretching and bending vibrations, respectively $[17,20]$. In MKN, those bands were weaker in contrast to those observed in raw kaolinite which suggest the interaction of $\mathrm{Al} / \mathrm{Si}-\mathrm{O}$ of $\mathrm{ka}$ olinite with $\mathrm{Fe}-\mathrm{O}$ bond for MKN's formation [3]. The Al-O-Si skeletal vibrations in kaolinite were denoted at $530 \mathrm{~cm}^{-1}$ and $460 \mathrm{~cm}^{-1}$ [19]. The spectrum of MKN2:1 and MKN5:1 showed a sharper band at $460 \mathrm{~cm}^{-1}$ than those in the MKN1:1 due to the larger kaolinite content in the former composites. For the iron oxide spectrum, the bands at $627 \mathrm{~cm}^{-1}$ to $542 \mathrm{~cm}^{-1}$ were associated with the $\mathrm{Fe}-\mathrm{O}$ bond stretching vibration [23]. The band at $627 \mathrm{~cm}^{-1}$ was almost diminished especially in MKN5:1 due to limited $\mathrm{Fe}-\mathrm{O}-\mathrm{Al}$ or $\mathrm{Fe}-\mathrm{O}-\mathrm{Si}$ bond formed within the composite [23]. Overall, FTIR analysis shows that all important bands of functional groups from the pristine material (kaolinite and iron oxide) were well-preserved in the composite. Meanwhile, the MB-loaded MKN (Figure 1(b)) showed a broad band at $3432 \mathrm{~cm}^{-1}$ associated with hydroxyl bonding with nitrogen $(\mathrm{O}-\mathrm{H}---\mathrm{N})$ in $\mathrm{MB}$ molecule $[2,24]$. The new band at $1625 \mathrm{~cm}^{-1}$ (Figure 1(b)) could be corresponds to the vibrations of unsaturated bond of $\mathrm{C}=\mathrm{N}^{+}\left(\mathrm{CH}_{3}\right)_{2}$ previously observed in $\mathrm{MB}$ spectra (Figure 1(c)). In addition, a strong intensity band at $1591 \mathrm{~cm}^{-1}$ (referring to $\mathrm{C}=\mathrm{C}$ or $\mathrm{C}=\mathrm{N}$ bonds) [25] and at region 1110 to $1006 \mathrm{~cm}^{-1}$ (heterocycle skeleton $(\mathrm{C}-\mathrm{N}$ and $\mathrm{C}-\mathrm{S}-\mathrm{C})$ ) from 
MB dye was also present in MB-loaded MKN (Figure 1(b)) [24,25]. The presence of these bands in MB loaded-MKN hence attributed to the successful adsorption of MB towards the composites' surface.

All MKNs demonstrated a fast magnetic separation (in less than 120 seconds, on average) as compared to kaolinite which need a high-speed centrifugation to settle down. The plot of IO and MKN produced a "S" shaped curve (Figure 2) which shows the near- superparamagnetic characteristic [26]. The magnetization (Ms), retentivity (Mr), and coercivity $(\mathrm{Hc})$ value was shown in Table 1 . The decrease of magnetic strength is attributed to the nonmagnetic characteristic of kaolinite, which is typical for most clays. All composites demonstrated a magnetic susceptibility value at par or above the previously reported value for magnetic clay $[2,12]$. The MKN1:1 composite showed the highest Ms among others due to a

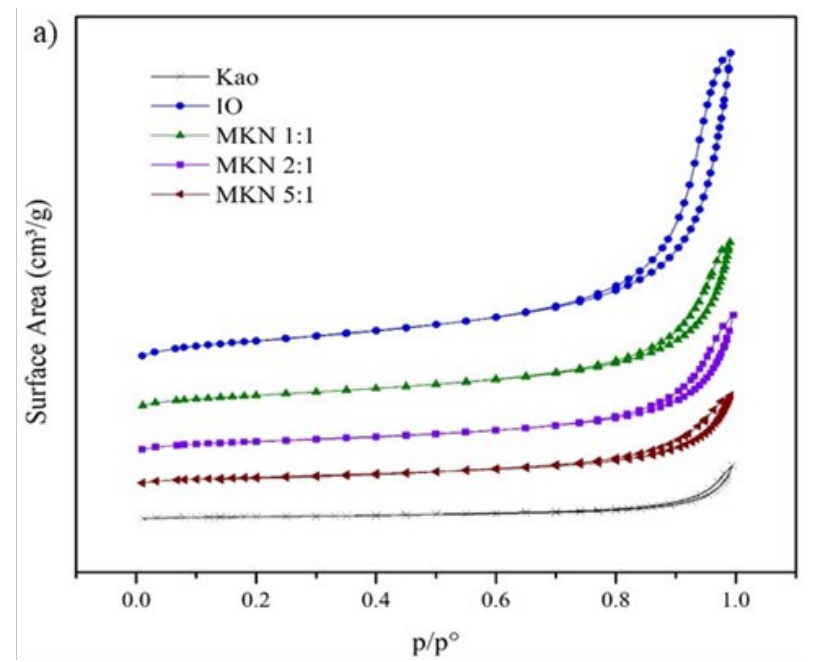

higher magnetic iron oxide content. Nevertheless, the non-zero coercivity value indicates the existence of magnetic storage, variation in particles size and the effect of cluster growth of iron oxides particles [27]. For example, although the Ms value of MKN5:1 was almost one-third of those obtained by MKN1:1, their difference in coercivity value was minor; suggesting an almost consistent particle size in each composite.

The surface area analysis demonstrated that the kaolinite has the lowest porosity but with the largest pore diameter (Table 2). According to the IUPAC classification, both kaolinite and iron oxide demonstrated a type IV isotherm (Figure 3(a)) [3,28] usually associated with the mesoporous structure. In addition, the pristine materials exhibit a $\mathrm{H} 3$ type hysteresis loop related to a slit-shape pore. These surface porosity features of pristine Kao and IO are well preserved within the MKNs (Figure 3(a)).

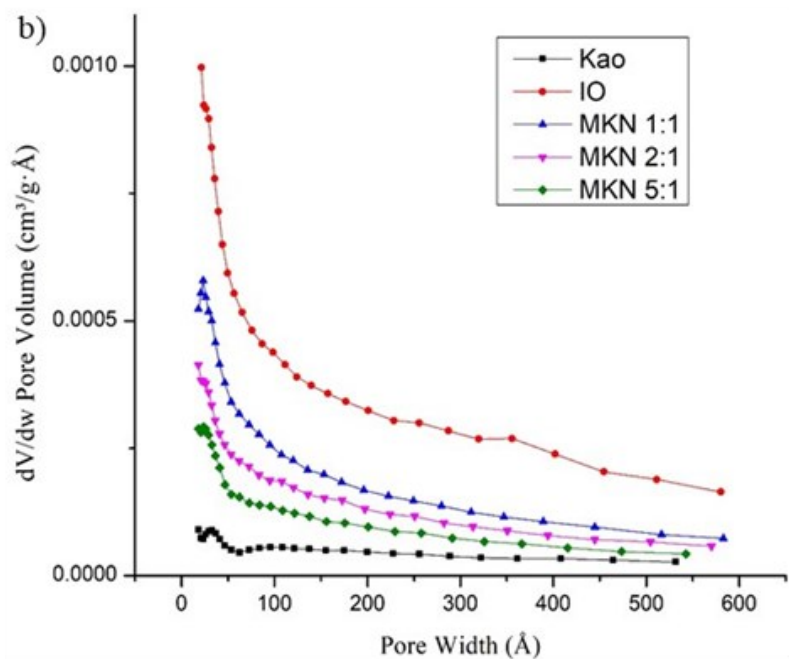

Figure 3. (a) $\mathrm{N}_{2}$ adsorption-desorption isotherms, (b) BJH pore size distribution.

Table 1. Magnetism properties of IO, MKN 1:1, MKN 2:1 and MKN 5:1.

\begin{tabular}{lcccc}
\hline Sample / Characteristic & IO & MKN 1:1 & MKN 2:1 & MKN 5:1 \\
\hline Magnetisation, Ms (emu/g) & 66.64 & 35.99 & 21.41 & 12.26 \\
Coercivity, Hc (G) & 62.56 & 28.86 & 26.75 & 22.35 \\
Retentivity, Mr (emu/g) & 6.952 & 2.073 & 1.271 & 0.6517 \\
\hline
\end{tabular}

Table 2 Surface area of kaolinite, IO and all MKNs.

\begin{tabular}{lccc}
\hline Sample & $\begin{array}{c}\text { BET specific surface } \\
\text { area }\left(\mathrm{m}^{2} / \mathrm{g}\right)\end{array}$ & $\begin{array}{r}\text { Average pore volume } \\
\left(\mathrm{cm}^{3} / \mathrm{g}\right)\end{array}$ & $\begin{array}{c}\text { Average pore diameter } \\
(\AA)\end{array}$ \\
\hline Kaolinite (Kao) & 9.11 & 0.0423 & 188.99 \\
IO & 69.4 & 0.2506 & 144.39 \\
MKN 1:1 & 44.5 & 0.1327 & 122.81 \\
MKN 2:1 & 34.6 & 0.1709 & 129.14 \\
MKN 5:1 & 25.0 & 0.0705 & 117.21 \\
\hline
\end{tabular}


The high BET surface area of MKN 1:1 is contributed by the iron oxide nano-features evidenced by the high $d V / d w$ pore volume of iron oxide in the pore size distribution (Figure 3(b)). The incorporation of porous iron oxide in MKNs

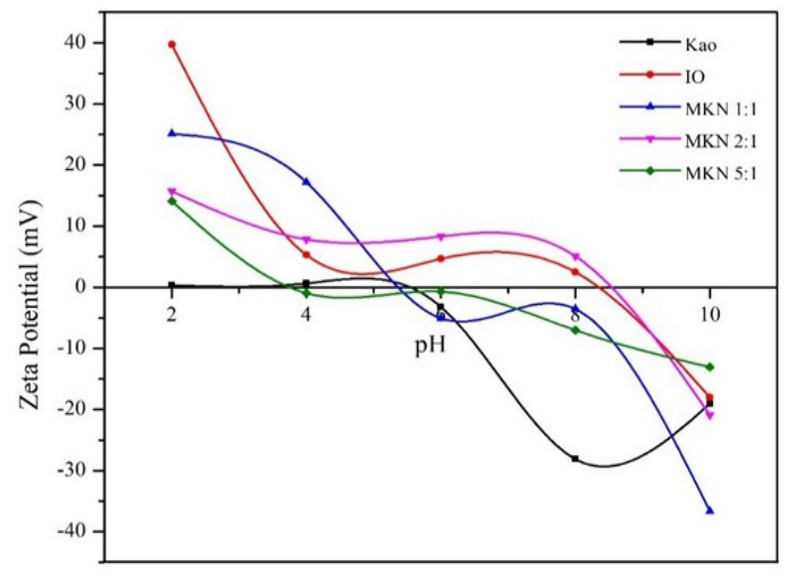

Figure 4 . The zeta potential curves for kaolinite, MKN 1:1, MKN 2:1 and MKN 5:1.
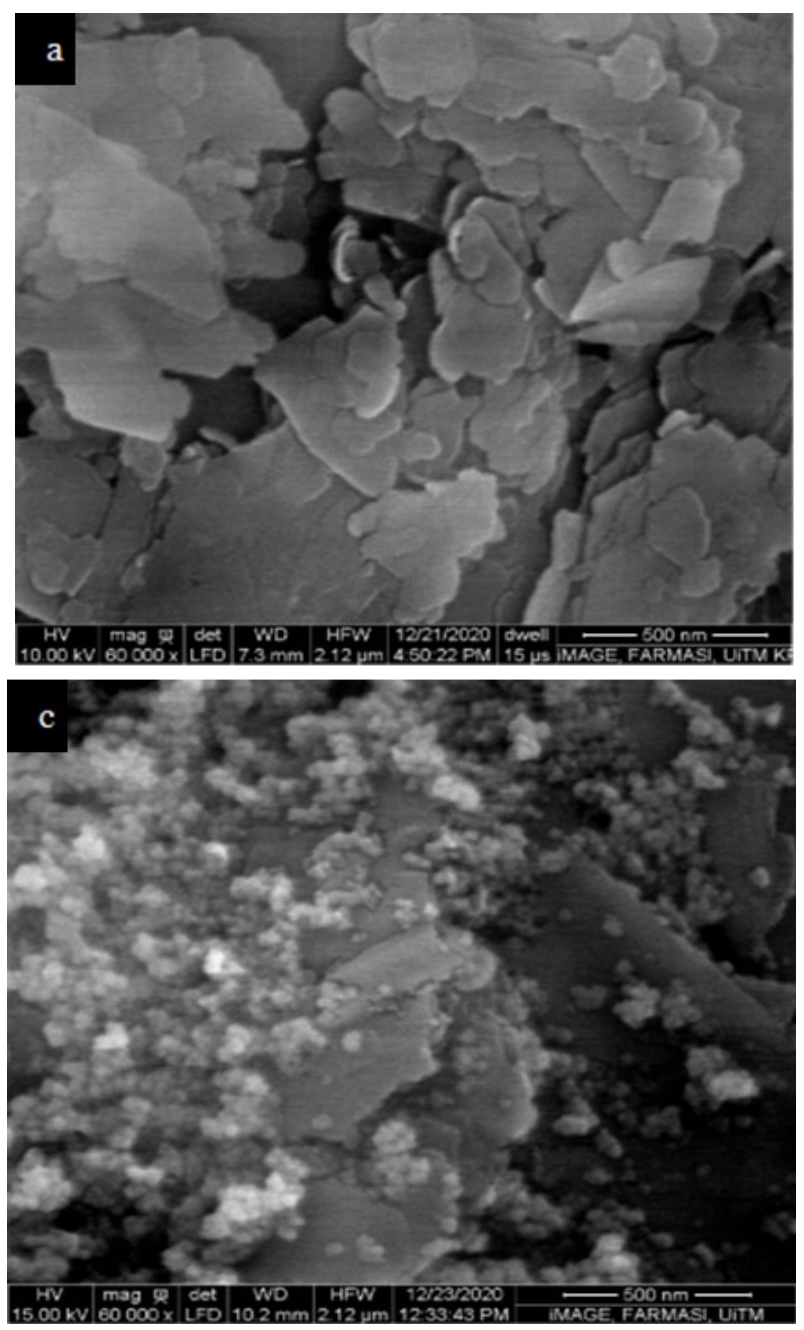

has resulted up to 4-fold increment of surface area (MKN 1:1) as compared to the pristine kaolinite. This finding hence signified the role of iron oxide in enhancing the surface porosity of clays' composite.

Meanwhile, the zeta potential measurements were used to describe the surface charge and the elucidation of the adsorption mechanism especially for electrostatic interaction $[14,29]$. Kaolinite has an isoelectric point (IEP) at around 4.6 (Figure 4). Kaolinite was known to have a positive surface charge at low $\mathrm{pH}$ but shifted to a negative surface charge as the $\mathrm{pH}$ increased [30]. The IEP for IO obtained in this study is relatively high (around 8.2) (Figure 4), but still closer to the previously reported value [31]. The MKNs recorded a different IEPs; in which at around $\mathrm{pH} 5.3$ (MKN 1:1), $\mathrm{pH} 8.5$ (MKN 2:1) and $\mathrm{pH} 3.7$ (MKN 5:1). The zeta potential values of MKN are a mixed and "inbetween" [31] of the zeta potential curve for the positive iron oxide surface and the neu-
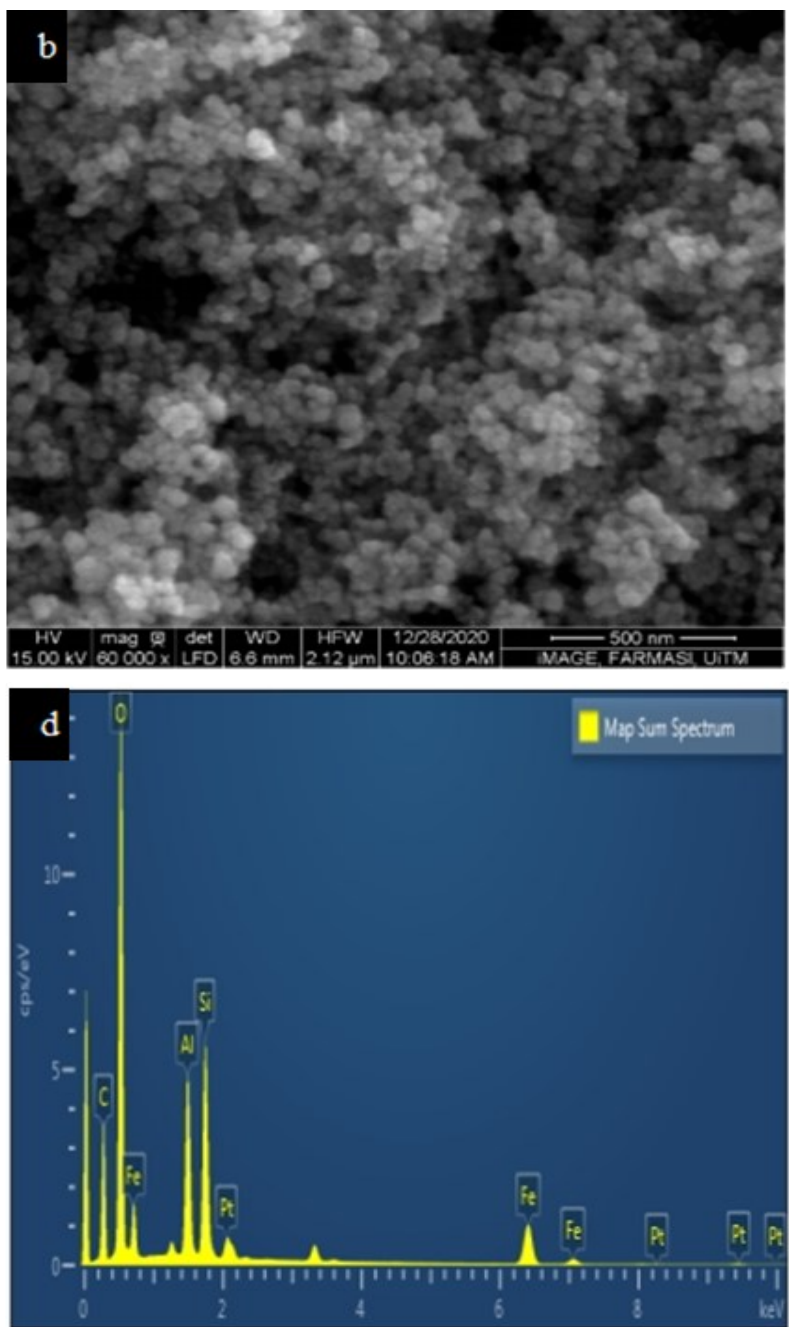

Figure 5. SEM images of (a) Kaolinite, (b) Iron Oxide, (c) Magnetic Kaolinite (MKN 1:1) and (d) EDX spectra of magnetic kaolinite (MKN 1:1). 
tral/negative kaolinite surface. At $\mathrm{pH} 2$ to 4 , all MKNs have a positive surface charge value $($ MKN 1:1 > MKN 2:1 > MKN 5:1) that resembles the surface charge profile of the IO (Figure 4). As more kaolinite component was present in MKN 5:1, this composite exhibits the least positive surface charge. However, at above $\mathrm{pH} \mathrm{4,} \mathrm{a}$ variety surface charge profile was observed. For example, at $\mathrm{pH} 6$ and 8, only MKN 1:1 exhibited a definite negative surface charge; despite it has the least kaolinite ratio as compared to the MKN 2:1 and MKN 5:1. This variation narrated the non-uniform surface chemistry in MKNs that is differs from the pristine components. The scattered and uneven distribution of iron oxide within the clays' surface could possibly cause a different protonationdeprotonation behaviour of the surface functional groups in the MKNs composite.

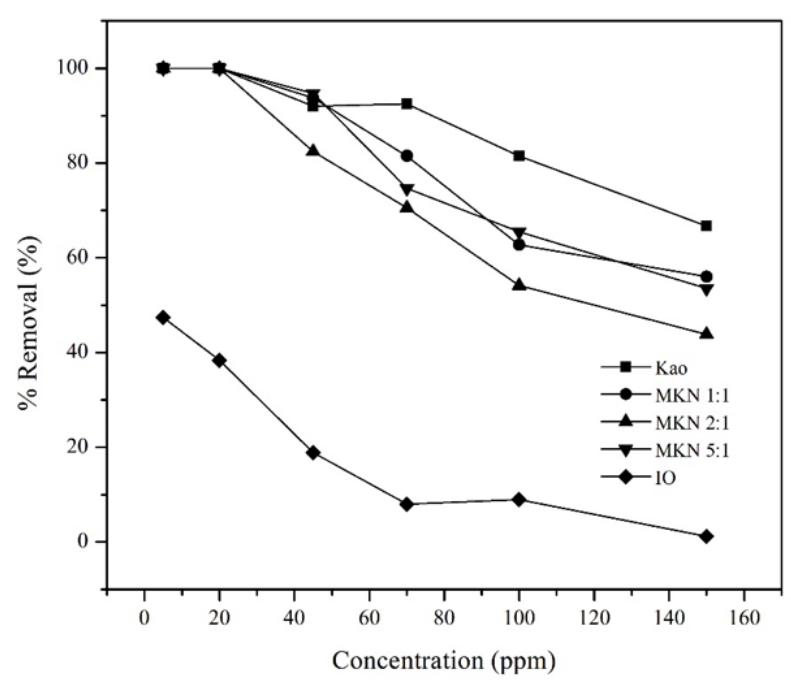

Figure 6 Percent removal of MB by all adsorbents at $\mathrm{pH} 6$.
The SEM images of kaolinite (Figure 5(a)) shows a smooth-edged surface with irregular platelets. Meanwhile, for IO, a uniform particle distribution was observed with the average particle size measured is between 30 to $35 \mathrm{~nm}$ (Figure 5(b)). In MKN 1:1 (Figure 5(c)), the IO particles were distributed homogeneously in clusters on the kaolinite's surface, but the accumulation did not entirely cover the clay's surface. These observations were similarly reported by other researchers, suggesting the deposition of iron oxide only occurs on kaolinite surface only [3,32]. The estimated particle size of IO embedded on the kaolinite surface is $39 \pm 2$ $\mathrm{nm}$. The presence of IO on kaolinite could also be confirmed from the EDX analysis of Fe element as shown in Figure 5(d).

\subsection{Adsorption Studies}

At initial concentration of 5 to $50 \mathrm{ppm}$, a $100 \%$ MB removal was recorded for all adsorbents (Figure 6). However, as the initial concentration increased, the dye removal efficiencies were decreasing. The MKN 1:1 showed the highest percent removal among all the composites. The primary adsorption mechanism of MB towards MKN are postulated to occur via electrostatic interaction [1,3,33] between the negative surface charge of MKN (Figure 4) towards the cationic MB molecules. The individual performance of kaolinite and IO against the MKN 1:1 was examined to deduce which component contribute the most towards the composites' dye removal efficiencies. Despite the kaolinite has a much lower specific surface area (Table 2), it recorded a higher percent removal (from 60 to $100 \%$ ) as compared to the poorly performed IO $(<50 \%)$ (Figure 6$)$. Thus,

Table 3. Parameters of adsorption isotherm model for Kaolinite, MKN 1:1, MKN 2:1 and MKN 5:1.

\begin{tabular}{|c|c|c|c|c|c|c|}
\hline \multirow{2}{*}{$\begin{array}{l}\text { Isotherm } \\
\text { Model }\end{array}$} & \multirow{2}{*}{ Linearised equation } & \multirow{2}{*}{ Parameters } & \multicolumn{4}{|c|}{ Adsorbent } \\
\hline & & & Kaolinite & MKN 1:1 & MKN 2:1 & MKN 5:1 \\
\hline \multirow{4}{*}{ Langmuir } & \multirow{3}{*}{$\frac{C_{e}}{q_{e}}=\frac{1}{\left(q_{\max } K_{L}\right)}+\frac{C_{e}}{q_{\max }}$} & $q_{\max }(\mathrm{mg} / \mathrm{g})$ & 11.71 & 18.15 & 11.9 & 14.95 \\
\hline & & $K_{L}(\mathrm{~L} / \mathrm{mg})$ & 4.9364 & 0.7046 & 0.5021 & 0.6098 \\
\hline & & $\mathrm{r}^{2}$ & 0.9989 & 0.9843 & 0.9915 & 0.9811 \\
\hline & $R_{L}=\frac{1}{1+K_{L} C_{0}}$ & $\begin{array}{l}R_{L} \text { value range } \\
\text { (min-max) }\end{array}$ & $\begin{array}{c}0.0077- \\
0.1041\end{array}$ & $\begin{array}{c}0.0072- \\
0.1423\end{array}$ & $\begin{array}{c}0.0072- \\
0.1460\end{array}$ & $\begin{array}{c}0.0069- \\
0.1470\end{array}$ \\
\hline \multirow{3}{*}{ Freundlich } & \multirow{3}{*}{$\log q_{e}=\log K_{f}+\frac{1}{n} \log C_{e}$} & $1 / n$ & 0.6743 & 0.6427 & 0.4146 & 0.4711 \\
\hline & & $K_{f}(\mathrm{~L} / \mathrm{g})$ & 1.6125 & 2.1842 & 2.2631 & 2.3725 \\
\hline & & $\mathrm{r}^{2}$ & 0.6654 & 0.6631 & 0.6269 & 0.6134 \\
\hline
\end{tabular}

$q_{e}=$ the quantity of adsorbed adsorbate per unit mass of adsorbent (mg.g-1); $C_{0}=$ initial concentration (mg.L-1); $C_{e}=$ equilibrium concentration (mg. $\left.\mathrm{L}^{-1}\right), K_{L}=$ Langmuir constants $\left(\mathrm{L}_{\mathrm{mg}} \mathrm{mg}^{-1}\right), q_{\max }=$ maximum monolayer adsorption $\left(\mathrm{mg} \cdot \mathrm{g}^{-1}\right) ; R_{L}=$ separation factor; $K_{F}=$ Freundlich constant at equilibrium $\left[\left(\mathrm{mg} . \mathrm{g}^{-1}\right)\left(\mathrm{L} \cdot \mathrm{mg}^{-1}\right)^{1 / \mathrm{r}}\right] ;$ and $n=$ degree of nonlinearity between solution concentration and adsorption. 
it is concluded that in terms of surface reactivity of MKN, the active sites in kaolinite could play the most significant role rather than those contributed by the iron oxide. Similar conclusion was also proposed by previous work involving magnetic bentonite [33]. The detailed molecular mechanism of dye degradation by iron oxide is still unclear [34] due to the complex interfacial adsorption and surface properties of the oxide shell. Further works on kinetics, thermodynamics, and atomic-level spectroscopic investigations of MKN are necessary to assist in elucidating the precise mechanism. However, at this stage it is still noteworthy that the presence of iron oxide in MKN has effectively facilitated the recoveries of spent clays which overcomes the current separation issues for largescale operation.

The MKN:1 demonstrates the highest maximum adsorption capacity value $(18.1 \mathrm{mg} / \mathrm{g})$ among all composites (Figure 7 and Table 3). A high shoulder on the adsorption isotherm also

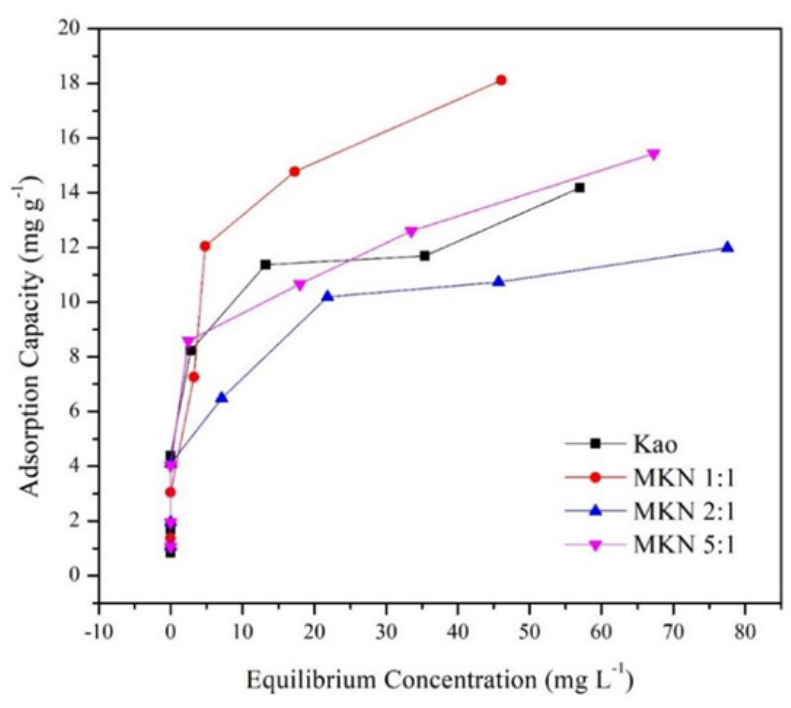

Figure 7. Adsorption equilibrium for Kao, MKN 1:1, MKN 2:1 and MKN 5:1. indicates a strong interaction between the adsorbents and the Methylene Blue (Figure 7). Experimental data of all adsorbents were best fitted to the Langmuir model attributed to the high regression coefficient value, $\mathrm{r}^{2}>0.98$ (Table 3). The fitness to Langmuir model indicates the monolayer adsorption characteristics and homogenous active sites [32], as opposed to the Freundlich model (multilayer adsorption and heterogonous surface sites). Meanwhile, the $R L$ value was found to be in the range of 0 to 1 , which implies a favourable MB dye adsorption (Table 3).

Although kaolinite has the lowest BET surface area (Table 2), its adsorption capacity is almost at par $(11.7 \mathrm{mg} / \mathrm{g})$ with other MKNs especially MKN 1:1 (18.1 mg/g) (Table 3). It is hence proposed that the surface active sites and surface porosity are both important in improving the dye removal capability of MKN. This finding is in parallel with the influence of a negative surface charge in enhancing the efficiencies of kaolinite and MKN 1:1 (Figure 4) as discussed earlier. Previous work also suggested that the surface porosity facilitates towards a higher maximum adsorption capacity for modified kaolinite [32]. However, for IO, particles aggregation and less abundance active sites may responsible for its low performance despite having the highest BET surface area (Table 2).

In terms of adsorption capacities, the performance of Malaysia's kaolinite and MKN were satisfactory considering the wide range of dyes' initial concentration used (Table 4). Optimisation of experimental conditions, (i.e. adsorbent loading and $\mathrm{pH}$ influence), are necessary to further evaluate the overall performance of MKN. Ascribed to its high availability, simple synthesis procedure and feasible recovery through the external magnetic field, this magnetic composite shall have great potential as a

Table 4. Comparison of clay-based adsorbent for removal of Methylene Blue.

\begin{tabular}{|c|c|c|c|c|c|}
\hline Material & $\begin{array}{l}\text { BET surface } \\
\text { area }\left(\mathrm{m}^{2} / \mathrm{g}\right)\end{array}$ & $\begin{array}{c}\text { Initial } \\
\text { concentration } \\
(\mathrm{mg} / \mathrm{L}) \\
\end{array}$ & $\begin{array}{l}\text { Optimum pH } \\
\text { of adsorption }\end{array}$ & $\begin{array}{c}\text { Removal percentage } \\
(\%) \text { or adsorption } \\
\text { capacity }(\mathrm{mg} / \mathrm{g})\end{array}$ & Ref. \\
\hline $\mathrm{Fe}_{3} \mathrm{O}_{4} /$ activated montmorillonite & 148 & 120 & 7 & $120 \mathrm{mg} / \mathrm{g}$ & {$[3]$} \\
\hline Iron oxide-pillared montmorillonite & 139 & 50 & 6 & $41 \%$ & {$[35]$} \\
\hline Iron pillared montmorillonite & 211 & 98 & 6 & $40 \%$ & {$[36]$} \\
\hline Magnetic kaolinite nanotubes & 60.8 & $10-20$ & 7 & $94 \%$ & [37] \\
\hline Natural kaolinite (Iraq) & 35.6 & $10-120$ & 8 & $240 \mathrm{mg} / \mathrm{g}$ & {$[1]$} \\
\hline Magnetic kaolinite & 26.9 & $1-5$ & $\mathrm{~N} / \mathrm{G}$ & $0.61 \mathrm{mg} / \mathrm{g}$ & {$[32]$} \\
\hline Kaolinite & 9.11 & $5-150$ & 6 & $100 \%(11.7 \mathrm{mg} / \mathrm{g})$ & This study \\
\hline Magnetic kaolinite nanocomposite & 44.5 & $5-150$ & 6 & $100 \%(18.1 \mathrm{mg} / \mathrm{g})$ & This study \\
\hline
\end{tabular}

$N / G$ : not given 
promising low-cost adsorbent for dye remediation process.

\section{Conclusions}

A magnetic kaolinite nanocomposite (MKN) with different kaolinite: iron oxide mass ratio was successfully prepared through a simple coprecipitation method. A higher iron oxide content in MKN has enhanced the BET surface area and its magnetism susceptibility, but less significant to boost the adsorption efficiencies towards Methylene Blue. Thus, for future synthesis of magnetic composite, an optimum clay: iron oxide composition should be considered for sufficient availability of surface active sites, without sacrificing its magnetic properties for a feasible magnetic separation. All MKNs have a $100 \%$ MB removal in which MKN 1:1 showed the highest maximum adsorption capacity (18.1 $\mathrm{mg} \mathrm{g}^{-1}$. Further spectroscopic, thermodynamic, and kinetic modelling studies are needed to elucidate the MB removal mechanism by MKN. This study provides new knowledge on the potential of magnetic clay nanocomposite derived from the natural local clay minerals for the treatment of dye contaminated water.

\section{Acknowledgement}

The authors would like to thank the Ministry of Higher Education of Malaysia for the financial support of this research through the Fundamental Research Grant Scheme (Grant No: FRGS/1/2019/STG07/UITM/02/15). The authors are grateful to the Nanotechnology \& Catalysis Research Centre (NANOCAT), University of Malaya and the Imaging Centre (iMAGE), Faculty of Pharmacy, Universiti Teknologi MARA for the technical assistance in characterisation analysis.

\section{References}

[1] Jawad, A.H., Abdulhameed, A.S. (2020). Mesoporous Iraqi red kaolin clay as an efficient adsorbent for methylene blue dye: Adsorption kinetic, isotherm and mechanism study. Surfaces and Interfaces, 18, 100422. DOI: 10.1016/j.surfin.2019.100422

[2] Alver, E., Brouers, F. (2020). Methylene blue adsorption on magnetic alginate / rice husk. International Journal of Biological Macromolecules, 154, 104-113. D O : 10.1016/j.ijbiomac.2020.02.330

[3] Chang, J., Ma, J., Ma, Q., Zhang, D., Qiao, N., Hu, M., Ma, H. (2016). Adsorption of methylene blue onto $\mathrm{Fe}_{3} \mathrm{O}_{4}$ /activated montmorillonite nanocomposite. Applied Clay Science, 119, 132-140. DOI: 10.1016/j.clay.2015.06.038
[4] Kandisa, R.V., Saibaba K.V.N., Shaik, K.B., Gopinath, R. (2016). Dye Removal by Adsorption: A Review. Journal of Bioremediation and Biodegradation, 7(6), 1000371. DOI: 10.4172/2155-6199.1000371

[5] Wahyuni, T., Prasetyoko, D., Suprapto, S., Qoniah, I., Bahruji, H., Dawam, A., Triwahyono, S., Jalil, A.A. (2019). Direct synthesis of sodalite from Indonesian kaolin for adsorption of $\mathrm{Pb} 2+$ solution, kinetics, and isotherm approach. Bulletin of Chemical Reaction Engineering and Catalysis, 14(3), 502-512. DOI: 10.9767/bcrec.14.3.2939.502-512

[6] Mukhopadhyay, R., Bhaduri, D., Binoy, S., Ruhaida, R., Deyi, H., Rubina, K., Subhas, S., Biswas, J.K., Vithanage, M., Bhatnagar, A., Ok, Y.S. (2020). Clay-polymer nanocomposites: Progress and challenges for use in sustainable water treatment. Journal of Hazardous Materials, (383), 121125. DOI: 10.1016/j.jhazmat.2019.121125

[7] Abdullahi, T., Harun, Z., Hafiz, M., Othman, D., Nazri, K. (2019). Preliminary studies on hydrothermal synthesis of zeolite from Malaysian kaolinite clays. Malaysian Journal of Fundamental and Applied Sciences, 15(3), 421-425. DOI: 10.11113/mjfas.v15n3.1213

[8] Minerals and Geoscience Department Malaysia. (2013). Commodity Review: Kaolin. Malaysian Minerals Yearbook 2013, Ministry of Natural Resources and Environment Malaysia. MYB 2013 Preface.pmd (jmg.gov.my)

[9] Nasarah, S.A. (27th April 2021). Transforming The Nation's Mineral Resources Industry.

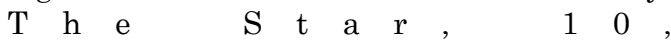
https://www.thestar.com.my/news/nation/202 1/04/27/transforming-the-nations-mineralresources-industry

[10] Chukwuemeka-Okorie, H.O., Ekemezie, P.N., Akpomie, K.G., Olikagu, C.S. (2018). Calcined corncob-kaolinite Combo as new sorbent for sequestration of toxic metal ions from polluted aqua media and desorption. Frontiers In Chemistry, 6(273), 1-13. DOI: 10.3389/fchem.2018.00273.

[11] Rusmin, R., Sarkar, B., Mukhopadhyay, R., Tsuzuki, T., Liu, Y., Naidu, R. (2022). Facile one pot preparation of magnetic chitosanpalygorskite nanocomposite for efficient removal of lead from water. Journal of Colloid and Interface Science, 608, 575-587. DOI: 10.1016/j.jcis.2021.09.109

[12] Chen, L., Zhou, C.H., Fiore, S., Tong, D.S., Zhang, H., Li, C.S., Ji, S.F., Yu, W.H. (2016). Functional magnetic nanoparticle/clay mineral nanocomposites: Preparation, magnetism and versatile applications. Applied Clay Science, 127-128, 143-163. DOI: 10.1016/j.clay.2016.04.009 
[13] Rahmanivahid, B., Naderi, F., Nayebzadeh, H. (2020). Removing methyl orange molecules from aqueous medium by magnetic nanoparticles: Evaluating adsorption factors, isotherms, kinetics and thermodynamics. Journal of Water and Environmental Nanotechnolo g y, 5 ( 1 ), $\quad 1-16$. D O I : 10.22090/jwent.2020.01.001

[14] Liu, H., Chen, W., Liu, C., Liu, Y., Dong, C. (2014). Magnetic mesoporous clay adsorbent: Preparation, characterization and adsorption capacity for atrazine. Microporous and Mesoporous Materials, 194, 72-78. DOI: 10.1016/j.micromeso.2014.03.038

[15] Izman, I.S., Baharin, S.N.A., Rusmin, R. (2020). Magnetic Kaolinite Composite for Lead Removal in Aqueous Solution. Malaysian Journal of Analytical Sciences, 24(1), 115124.

[16] Mirbagheri, N.S., Sabbaghi, S. (2018). A natural kaolin $/ \mathrm{Y}^{-}-\mathrm{Fe}_{2} \mathrm{O}_{3}$ composite as an efficient nano-adsorbent for removal of phenol from aqueous solutions. Microporous and Mesoporous Materials, 259, 134-141. DOI: 10.1016/j.micromeso.2017.10.007

[17] Panda, A.K., Mishra, B.G., Mishra, D.K., Singh, R.K. (2010). Effect of sulphuric acid treatment on the physico-chemical characteristics of kaolin clay. Colloids and Surfaces A: Physicochemical and Engineering Aspects, $363 \quad(1-3), \quad 98-104$. D O I : 10.1016/j.colsurfa.2010.04.022

[18] Mbey, J.A., Thomas, F., Razafitianamaharavo, A., Caillet, C., Villiéras, F. (2019). Applied Clay Science A comparative study of some kaolinites surface properties. Applied Clay Science, $172, \quad 135-145$. D O I : 10.1016/j.clay.2019.03.005

[19] Awwad, A.M., Amer, M.W., Al-aqarbeh, M.M. (2020). $\mathrm{TiO}_{2}$-kaolinite nanocomposite prepared from the Jordanian Kaolin clay: Adsorption and thermodynamics of $\mathrm{Pb}$ (II) and $\mathrm{Cd}$ (II) ions in aqueous solution. Chemistry International, 6(4), 168-178. DOI: 10.5281/zenodo.3597558

[20] Chai, J., Au, P., Mubarak, N.M., Khalid, M., $\mathrm{Ng}$, W.P. (2020). Adsorption of heavy metal from industrial wastewater onto low-cost Malaysian kaolin clay-based adsorbent. Environmental Science and Pollution Research, 27, 13949-13962. DOI: 10.1007/s11356-02007755-y

[21] Magdy, A., Fouad, Y.O., Abdel-Aziz, M.H., Konsowa, A.H. (2017). Synthesis and characterization of $\mathrm{Fe}_{3} \mathrm{O}_{4} /$ kaolin magnetic nanocomposite and its application in wastewater treatment. Journal of Industrial and Engineering Chemistry, 56, 299-311. DOI: 10.1016/j.jiec.2017.07.023
[22] Tokarčíková, M., Tokarský, J., Kutláková, K.M., Seidlerová, J. (2017). Testing the stability of magnetic iron oxides/kaolinite nanocomposite under various $\mathrm{pH}$ conditions. Journal of Solid State Chemistry, 253, 329-335. DOI: $10.1016 /$ j.jssc.2017.06.004

[23] Belachew, N., Getahun, B. (2020). Synergy of magnetite intercalated bentonite for enhanced adsorption of Congo Red dye. Silicon, 12(3), 603-612. DOI: 10.1007/s12633-01900152-2

[24] Li, Z., Wang, C.J., Jiang, W.T. (2010). Intercalation of methylene blue in a high-charge calcium montmorillonite - An indication of surface charge determination. Adsorption Science and Technology, 28(4), 297-312. DOI: 10.1260/0263-6174.28.4.297

[25] Ovchinnikov, O.V., Evtukhova, A.V., Kondratenko, T.S., Smirnov, M.S., Khokhlov, V.Y., Erina, O.V. (2016). Manifestation of intermolecular interactions in FTIR spectra of methylene blue molecules. Vibrational Spectroscopy, 86, 181-189. DOI: 10.1016/j.vibspec.2016.06.016

[26] Rusmin, R., Sarkar, B., Tsuzuki, T., Kawashima, N., Naidu, R. (2017). Removal of lead from aqueous solution using superparamagnetic palygorskite nanocomposite: Material characterization and regeneration studies. Chemosphere, 186, 1006-1015. DOI: 10.1016/j.chemosphere.2017.08.036

[27] Yamaura, M., Alves, D. (2013). Synthesis and characterization of magnetic adsorbent prepared by magnetite nanoparticles and zeolite from coal fly ash. Journal of Material Science, 48, 5093-5101. DOI: 10.1007/s10853-0137297-6

[28] Huang, G.Q., Qi, G.J., Gao, T.Y., Zhang, J., Zhao, Y.H. (2020). Fe-pillared montmorillonite as effective heterogeneous Fenton catalyst for the decolorization of methyl orange. Journal of Chemical Sciences, 132(1), 116. DOI: $10.1007 / \mathrm{s} 12039-020-01820-2$

[29] Cottet, L., Almeida, C.A.P., Naidek, N., Viante, M.F., Lopes, M.C., Debacher, N.A. (2014). Adsorption characteristics of montmorillonite clay modified with iron oxide with respect to methylene blue in aqueous media. Applied Clay Science, 95, 25-31. DOI: 10.1016/j.clay.2014.03.023

[30] Hoor, Y.Q., Au, P.I., Mubarak, N.M., Khalid, M., Jagadish, P., Walvekar, R., Abdullah, E.C. (2020). Surface force arising from adsorbed graphene oxide in kaolinite suspensions. Colloids and Surfaces A: Physicochemical and Engineering Aspects, 592, 124592. DOI: $10.1016 /$ j.colsurfa.2020.124592 
[31] Mandel, K., Granath, T., Dembski, S., Sextl, G. (2015). Surfactant free superparamagnetic iron oxide nanoparticles for stable ferrofluids in physiological solutions. Chemical Communications, 51, 2863-2866. DOI: $10.1039 / \mathrm{c} 4 \mathrm{cc} 09277 \mathrm{e}$

[32] Shikuku, V.O., Mishra, T. (2021). Adsorption isotherm modeling for methylene blue removal onto magnetic kaolinite clay: a comparison of two-parameter isotherms. Applied Water Science, 11 (6), 1-9. DOI: 10.1007/s13201-02101440-2

[33] Lou, Z., Zhou, Z., Zhang, W., Zhang, X., Hu, X., Liu, P., Zhang, H. (2015). Magnetized bentonite by $\mathrm{Fe}_{3} \mathrm{O}_{4}$ nanoparticles treated as adsorbent for methylene blue removal from aqueous solution: synthesis, characterization, mechanism, kinetics and regeneration. Journal of the Taiwan Institute of Chemical Engineers, 49, 199-205. DOI: 10.1016/j.jtice.2014.11.007

[34] Mu, Y., Jia, F., Ai, Z., Zhang, L. (2017). Iron oxide shell mediated environmental remediation properties of nano zero-valent iron. Environmental Science: Nano, 4(1), 2745. DOI: $10.1039 / \mathrm{C} 6 \mathrm{EN} 00398 \mathrm{~B}$
[35] Tireli, A.A., Guimarães, I.d.R., Terra, J.C.d.S., Silva, R.R.d., Guerreiro, M.C. (2015). Fenton-like processes and adsorption using iron oxide-pillared clay with magnetic properties for organic compound mitigation. Environmental Science and Pollution Research, 22, 870-881. DOI: 10.1007/s11356-014-2973-x

[36] Tireli, A.A., Marcos, F.C.F., Oliveira, L.F., Guimarães, I.d.R., Guerreiro, M.C., Silva, J.P. (2014). Influence of magnetic field on the adsorption of organic compound by clays modified with iron. Applied Clay Science, 97-98, 1-7. DOI: 10.1016/j.clay.2014.05.014

[37] Xu, H., Liu, J., Chen, P., Shao, G., Fan, B., Wang, H., Chen, D., Lu, H., Zhang, R. (2018). Preparation of Magnetic Kaolinite Nanotubes for the Removal of Methylene Blue from Aqueous Solution. Journal of Inorganic and Organometallic Polymers and Materials, 28(3), 790-799. DOI: 10.1007/s10904-0170728-0 